ARXIU D'ETNOGRAFIA DE CATALUNYA, N.॰ 3, 1984

\title{
PIUS FONT I QUER: UN PRECURSOR DE L'ETNOBOTÀNICA FARMACÈUTICA A CATALUNNYA *
}

\author{
J. Ma CAMARASA
}

- Conferència pronunciada el 18 de desembre de 1982 amb motiu de la ciausura de les Primeres Jornades d'Antropología de la Medicina de Tarragona

Arxiu d'Etnografia de Catalunya, $n^{\circ} 3,1984,176-186$

ISSN: 0212-0372. EISSN: 2014-3885

http://antropologia.urv.cat/revistarxiu 
Excm. Sr. Rector de la Universitat de Barcelona

Sr. Director de la Facultat de Lletres

Sr. President de l'Institut Català d'Antropologia

Amics tots:

Les meves primeres paraules han de ser inexcusablement l'expressió del meu regraciament als organitzadors d'aquestes Jornades d'Antropologia de la Medicina per haver-me honorat amb l'encàrrec de glossar aquí la figura eminent $\mathrm{i}$ estimada de Pius Font i Quer. L'encàrrec, certament, $m$ 'ha afalagat per una banda i m'ha desconcertat per una altra. No cal que us expliqui les raons de l'afalagament. En el capítol del desconcert deixeu-me reconèixer que no estic gaire convençut de ser el glossador més idoni de Pius Font i Quer. Tant en el terreny científic com en el personal penso que hi ha persones que en podrien parlar més de primera mà per haver-ne estat els deixebles directes o els continuadors de les seves línies de recerca, per haver-lo conegut personalment, per haver-hi conviscut, per haver-hi collaborat. Jo, tanmateix, pertanyo ja a la primera generació de botànics que no coneguérem el seu mestratge directe per tal com arribàrem a les aules universitàries els primers anys seixanta, entorn de la data de la seva mort.

És clar que també és veritat - $\mathrm{i}$ vull creure que així ho han pensat els organitzadors d'aquestes Jornades- que l'obra de Font i Quer ha marcat una emprempta tan profunda i important a la botànica catalana que ha estat i serà encara molts anys punt dé referència obligat. I no sols per als botànics estrictament sinó per tots els que s'interessen d'una manera o d'una altra pel món de les plantes des de qualsevol punt de vista, com és el cas de les seves aplicacions terapèutiques, o per aquells que es preocupen de l'organització de la recerca científica en un país petit $i$ gasiu com el nostre.

Ja he dit que no tinc records personals de Pius Font i Quer. Sí que en tinc, però, i molt vívids, de l'experiència colpidora de fins a quin punt es feia palpable encara la seva presència, anys després de la seva mort, en cada sala, en cada llibre, en cada plec d'herbari d'aquell Institut Botànic de Barcelona, que ell havia creat.

Alguns estudiants de Ciències Biològiques ens acostavem de tant en tant, aquell 1966 de la Caputxinada, a l'Institut Botànic; ho feiem com si ens acostessim a un santuari on es preservessin els secrets d'una ciència oculta. Segurament no ens equivocavem de gaire perquè certament només in extremis havia estat possible salvar del naufragi alguna cosa del treball de més de vint anys d'un científic eminent que el 1939 havia estat bandejat de tots els seus càrrecs $\mathrm{i}$ fins $\mathrm{i}$ tot processat com si fos un malfactor. 
En el nostre itinerari iniciàtic, tot preparant campanyes d'exploració botànica de diferents indrets del país anàvem trobant constantment plecs de plantes recollides pel doctor Font, separates de revistes de múltiples autors dedicades en els termes més respectuosos i afectuosos al doctor Font, les premses que s'havia endut d'excursió el doctor Font, ... Poc a poc, aquell nom que al començament no era per a nosaltres més que el nom de l'autor del «Diccionario de Botánica» que haviem de consultar sovint, esdevenia una figura omnipresent, estimada i respectada. Poc a poc anàvem esbrinant l'entrellat d'una vida dedicada a la ciència que les tràgiques consequèències de la guerra i de la dictadura franquista haviem marginat i condemnat a l'oblit, però que, a desgrat d'això, havia estat al llarg de prop de cinquanta anys el mestre indiscutible de la botànica catalana i el creador d'una escola que perllonga la seva força creadora.

Però evidentment no és pel seu destacat paper a la botànica catalana - o, si més no, no únicament per això- que voleu retre homenatge avui a Pius Font i Quer. Ho feu, molt principalment, perquè Font i Quer fou d'alguna manera precursor de la recerca en el camp que és objecte d'aquestes Jornades. Encara que no fos en tota la seva amplitud sinó més en l'àmbit restringit de l'ús terapèutic de les plantes $i$ en el de les tradicions i els usos lligats a les plantes medicinals. Estic segur que molts de vosaltres teniu el seu llibre «Plantas Medicinales» com autèntic llibre de capçalera; certament ho mereix, però és que aquest mateix llibre és també fonamental des d'altres punts de vista, encara que només fos pel bé de Déu de noms vulgars de plantes en català, castellà, éuscar i galaico-portuguès que, com sabeu, conté i que són de considerable interès per als estudiosos de les llengües de la Península Ibèrica.

Perquè Font i Quer, a més de ser el més gran dels botànics catalans de tots els temps, és també un personatge que adreçà esforços en múltiples direccions per a relligar el coneixement del món de les plantes amb el món dels homes, i la seva obra té transcendència tant en la terminologia científica com en la farmacognòsia, tant en la filologia com en l'organització de la recerca. Com ha dit Ramon Margalef, fou un dels caps més ben construits del nostre país. I són precisament alguns d'aquests aspectes, en certa manera una mica marginals a la seva biografia científica, centrada en el seu treball botànic, els que possiblement us poden interessar més a vosaltres i els que tractaré de posar de relleu en una pinzellada biogràfica tal vegada lleument heterodoxa però plena d'afecte $\mathrm{i}$ de respecte per la figura de Pius Font $\mathrm{i}$ Quer.

Heterodoxa, però potser no tant, per tal com foren algunes de les seves qualitats no estrictament rellevants en el camp de la botànica les que feren possible el seu valuosíssim treball de botànic. Així, per exemple, sense el seu gran tremp d'organitzador del treball científic mai no hagués reeixit a crear pràcticament del no res un centre com l'Institut Botànic que constituís una plataforma de recerca, de documentación i de formació de nous investigadors. Cal pensar que quan el 1916 fou nomenat Naturalista Agregat del Museu de Ciències Naturals de Barcelona, encarregat d'organitzar els herbaris, la feina que hom esperava d'ell no anava més enllà de la preparació d'un Herbari Normal de Catalunya a partir del miler i mig de plantes de què disposava el Museu i les que puguessin arreplegar-se en unes quantes campanyes no massa ambicioses, per a les quals, inicialment, ni tan sols hi havia dotació o les que poguessin obtenir mercès a donacions. Al llarg de prop de vint anys, de 1916 a 1935, i a desgrat dels entrebancs considerables determinats pels set anys de dictadura de Primo de Rivera (1923-1930), anà madurant el projecte d'un centre de recerca que excedís la curta i provinciana ambició inicial fins a assolir la creació d'un centre com l'Institut Botànic, que el 1936 era perfectament comparable a la majoria dels centres equivalents d'Europa i Amèrica $i$ que encara avui, malgrat decennis de marginació per part de les autoritats municipals de Barcelona $\mathrm{i}$ de la sistemàtica negligència de l'estructura estatal de recerca, manté una decorosa dignitat dins de les limitacions dels mitjans de que pot disposar. En aquella vintena d'anys (1916-1936) hom passà d'una Secció d'Herbaris del Museu de Ciències Naturals de Barcelona amb un miler i mig de plecs de plantes de Catalunya i una biblioteca pràcticament inexistent a un Institut Botànic amb uns herbaris que contenien 226.000 plecs de plantes de tot el món (amb una especial incidència de les dels Països Catalans, resta de la Península Ibèrica, Africa del Nord i Occitània) entre els quals figuraven tots els herbaris clàssics de Catalunya (Costa, Trèmols, Vayreda, Cadevall, Sennen, Salvador -incorporat el 1937), amb una biblioteca important, uns laboratoris discrets $\mathrm{i}$ un personal de vàlua reconeguda internacionalment.

I això en mig d'un context que, en el millor dels casos, l'afavoria amb migradesa $i$ en el pitjor s'esforçava en frenar-lo. Mai, si no és en els dos o tres últims anys, amb tots els pronunciaments favorables.

Si primer coneix uns anys d'ascensió fulgurant (1916-1921) en que passa de Naturalista Agregat honorari a Director del Museu de Ciències Naturals de Barcelona passant successivament pels càrrecs d'Auxiliar Tècnic de Botànica (1917), Conservador de Botànica (agost de 1918) i Regent de les Seccions de Fanerogàmia, Criptogàmia $\mathrm{i}$ Geografia Botànica (desembre de 1918), el 1922 ha de conèixer la fel d'una derrota injusta en les oposicions a la càtedra de Botànica de la Facultat de Farmàcia de la Universita de Barcelona per raons polítiques i el seu allunyament de la Universitat fins que el 
1933 s'incorpora a la Universitat Autònoma. En realitat, els anys d'aquesta ascensió primerenca de Font i Quer coincideixen amb els anys d'expansió del Museu de Ciències Naturals de Barcelona i de la Junta de Ciències Naturals en passar aquesta, el 1917, de purament municipal a mixta, amb intervenció de l'Ajuntament de Barcelona, de la Diputació i, a partir de 1920, de la Mancomunitat. Però, tot i l'empenta de 1917, les institucions barcelonines no foren especialment generoses amb el Museu d'Història Natural, i el mateix Font i Quer, a la Memòria del curs $1921 / 22$, s'exclamava: «Una vegada més enguany ens hem de doldre del mateix (...) El pressupost de la Junta de Ciències Naturals fou fortament disminuit perquè l'Excelentíssim Ajuntament de Barcelona no ens donà més que una part de la meitat condicionada de les subvencions de material i personal». Això no li impedí tanmateix unir a la seva activitat administrativa en aquests anys un considerable nombre de campanyes d'exploració per Catalunya, el Pirineu Aragonès, les illes Pitiuses, el migjorn valencià, Múrcia, Mallorca, Navarra i Aragó Central, així com publicar una cinquantena de treballs.

Es en el curs de les seves campanyes d'exploració botànica que comença a interessar-se no sols per les plantes que recull i determina (més d'una vegada abans que cap altre botànic) sinó també per les relacions del món de les plantes amb el món dels homes que hi viuen en contacte amb elles, que se'n serveixen, que en fan símbols o que simplement les coneixen i els donen nom. Ja el 1916 publicava al Butlletí del Centre Excursionista del Bages un article titulat "La ciència d'en Sovatger", en que recull una part dels coneixements que en Sovatger, un pastor d'Horta de Sant Joan, habilísimm caçador de cabres salvatges (d'on li venia el renom de Sovatger), que no sols coneixia les propietats medicinals o màgiques de moltes plantes sinó que tenia uns coneixements de la distribució geogràfica i topogràfica de moltes espècies que causà l'admiració de Font $\mathrm{i}$ Quer. El record d'en Sovatger i dels seus coneixements acompanyà tota la seva vida Pius Font i Quer, que hi dedicà encara uns records en el seu darrer llibre, el vostre conegut «Plantas Medicinales», i que tinguè sempre una gran confiança en el bon sentit per al reconeixement de plantes de recollectors sense gran instrucció, com per exemple Enric Gros, dels quals feu companys d'excursí i de qui sempre estava disposat a aprendre, en una actitud desafortunadament no prou comú llavors $\mathrm{i}$ ara en el món universitari. En molts dels treballs de Font $\mathrm{i}$ Quer es troben indicacions sobre la nomenclatura vulgar de les plantes que troba, sobre els usos que es fa de les plantes indicades en els llocs que visita, de les virtuts que els són atribuides o de les tradicions que hi estan vinculades. Sovint comenta les raons de les confusions entre plantes diferents en la nomenclatura popular a causa de trets comuns o de propietats que els són atribuides.
Una revisión a fons dels seus treballs botànics amb ulls d'antropòleg hi pot pouar encara un gavadal d'informacions, tot i que certament moltes d'elles, si no majoria, queden recollides també en el tantes vegades repetit «Plantas Medicinales».

Però reprenem el fil cronològic. Haviem deixat aquest fil en un punt crític: el de les oposicions a la càtedra de botànica de la Facultat de Farmàcia de la Universitat de Barcelona. Pius Font i Quer, farmacèutic des del 1910 , encara que prèviament havia estudiat ciències químiques, havia llegit la seva tesi doctoral «Ensayo fitotopográfico de Bages» el 1914. El 1917 havia començat a professar classes de botànica a la Facultat de Farmàcia de la Universitat de Barcelona i, després d'un parèntesi el 1918, fou primer nomenat professor auxiliar temporal (1919-1920) i després encarregat de la càtedra de botànica descriptiva (1920-1921 i 1921-1922). Precisament en aquest moment en que arriba a la plenitut de la seva carrera el tribunal d'oposicions li barra el pas definitiu a la cátedra amb gran escàndol de tots els que coneixien la diferència de talla científica entre Font i Quer i el seu competidor, a qui el tribunal atorgà la càtedra. Davant de la seva postergació en Font $\mathrm{i}$ Quer no té altra alternativa digna que dimitir del seu càrrec d'auxiliar. No tornaria a la Universitat fins que el 1933 fou cridat a la Universitat Autònoma com a professor agregat permanent de botànica farmacèutica.

Entremig, però, la Dictadura de Primo de Rivera havia d'afegir nous entrebancs al normal desplegament de l'activitat cientifica de Font $\mathrm{i}$ Quer. Per una banda, en perturbar primer el normal funcionament de la Mancomunitat i finalment suprimir-la (1925), la precarietat dels recursos del Museu de Ciències Naturals fou encara més gran que en el període anterior en que, com ja hem vist, no eren pas sobrats. Per acabar-ho d'adobar, el 1926 és ascendit a Farmacèutic major (era farmacèutic militar des del 1911) i té que triar destí fora de la plaça on estava destinat en aquell moment, és a dir de Barcelona. Font i Quer jugà fort i optà per anar-se'n al protectorat espanyol del Marroc, tot just pacificat, territori pràcticament desconegut pels botànics europeus del seu temps. Ell en serà el primer explorador sistemàtic al llarg de quatre anys amb esporàdiques escapades a Barcelona. Serà en aquests anys de maltempsada quan demostrarà al màxim la seva capacitat per a treure profit de les condicions més adverses. No sols es consagra com una figura indiscutible de la botànica-nord-africana sinó que reix a enriquir els herbaris del Museu de Ciències Naturals pràcticament sense despeses. Anuncià el seu viatge al Marroc a les principals revistes botàniques del món i oferí colleccions de plantes recoHectades i determinades per ell sota el nom d'Iter maroccanum a tothom qui vulgués subscriure una quantitat per ajudar 
a les despeses de l'expedició; els subscriptors foren nombrosos i uns en metàlic i altres per intercanvi d'altres exsiccata (exsiccata és el nom que donen els botànics a aquestes colleccions normalitzades de plantes seques) contribuiren a enriquir notablement els herbaris del futur Institut Botànic i contribuiren a fer neixer un ambiciós projecte que hagués hagut de convertir-se en l'eix dels treballs de l'Institut Botànic si la guerra civil no ho hagués frustrat el 1936: la Flora Occidentalis. Ês a dir, la flora de l'extrem mediterrani des dels Alps fins a l'Atlas. No fou possible però tanmateix els treballs sobre flora marroquina de Font i Quer passen de la trentena.

També al Marroc es preocupà d'aspectes no estrictament botànics en les seves recerques, bé que l'obstacle del desconeixement de la llengua dels berebers del Rif $i ́$ dels àrabs del Garb limitava seriosament les possibilitats de Font i Quer qui, tanmateix, no deixà de notar la presència de tal o tal planta als mercats o la micofòbia tant dels àrabs com dels berebers.

El nou nomenament de Font i Quer com a Director del Museu de Ciències Naturals enceta el 1930 la darrera etapa de la seva activitat com a organitzador i orientador de la recerca naturalística a Catalunya. Aquesta etapa, que havia de ser especialment fecunda, es veurà trágicament perturbada el $1936 \mathrm{i}$ definitivament interrompuda el 1939. Abans, però, encara havia de tenir temps per a dur a terme empreses com el Pla Quinquenal Micologic de Catalunya (1931-1935) mercès el qual el nombre de macromicets, és a dir de fongs amb aparell reproductor diferenciable a simple vista (o bolet), coneguts a Catalunya passà de 627 a 1458 , és a dir que gairebé es triplicà $\mathrm{i}$ que duguè a Catalunya els màxims especialistes europeus de la micologia. Bé que mai no hi tingué una dedicació d'especialista el món dels fongs interessà vivament Font $\mathrm{i}$ Quer qui, per altra banda, establí la distribució de la micofilia $i$ la micofàgia a la península ibèrica $i$ recollí nombroses dades sobre usos alimentaris i psicotròpics dels fongs, toxicitat, tradicions que hi eren vinculades, etc...

El 1932 torna encara al Marroc, i al 1935 va a Ifni. Del 1931 al 1934 exerceix la presidència de la Institució Catalana d'Història Natural. Però l'esdeveniment clau d'aquest període és el retorn de Font i Quer a la Universitat el 1933. Aquest cop ho feu per la porta gran en cridar-lo la Universitat Autònoma de Barcelona com a professor agregat permanent de Botànica Farmacèutica. Hom li donà carta blanca per a escollir els seus coHaboradors i ell trià dos joves alemanys, l'un fanerogamista i l'altre criptogamista, Werner Rothmaler i Rolf Singer. Singer esdevingué després (i és encara) un dels millors micòlegs europeus; Rothmaler, després de collaborar amb Font i Quer en els inicis de la seva projectada Flora Occidentalis (1934-1936), esdevingué un dels millors floristes alemanys i morí el 1962 éssent director de
1'Institut de Biologia de la Universitat Ernst-Moritz-Ardnt de Greifswald, a Pomerània, a la República Democràtica Alemanya.

Una darrera empresa notable, que no puc deixar d'esmentar aquí encara que afecta més exclusivament els interessos botànics de Font $\mathrm{i}$ Quer, fou l'excursió de la Station Internationale de Geobotanique Méditerranéenne et Alpine (SIGMA), amb Josias Braun-Blanquet al front, per terres de Catalunya. Es pot dir que aquesta excursió posa els fonaments de la fitosociologia catalana, $\tan$ desenvolupada a partir dels inicis dels anys cinquanta per Oriol de Bolòs, actual director de l'Institut Botànic, i els seus deixebles.

Font i Quer es planteja doncs els anys trenta l'establiment sobre bases sòlides - ara que li ho permet un prestigi sòlidament adquirit, una experiència viscuda dels problemes de la recerca naturalística i una situació acadèmica privilegiada- d'un complexe de recerca, formació i documentació en un camp científic específic, que no té parió a Catalunya. Ês cert que compta amb una tradició arrelada de prop de tres segles que no existeix en altres camps científics, però no ho és menys que en no pocs aspectes les seves propostes són totalmente innovadores. Els bolets, abans d'ell, havien estat objecte més d'estralls gastronòmics que no d'estudi i la fitosociologia era una ciència nou-nada quan ell la introdueix a Catalunya juntament amb Huguet del Villar bé que seguint metodologies força diferents de les d'aquest. Amb la creació de l'Institut Botànic el 1935 i les activitats que pontem ressenyades s'acompleixen els objectius de recerca i documentació; resta la formació. Pel que fa a aquest punt concep uns cursos de vacances per als estudiants de la seva càtedra que havien de consistir en l'exploració sistemática, primer florística i després fitosociològica, d'una àrea mal coneguda de la península Ibèrica. El primer d'aquests curşos s'inicià el 29 de juny de 1936 i havia de durar fins al 10 d'agost. Quan a finals de juny de 1936, amb dos ajudants $\mathrm{i}$ cinc alumnes, dues noies $\mathrm{i}$ tres nois, emprenia viatge cap a Orihuela del Tremedal, a la serra d'Albarracín, poc podia pensar Font i Quer que emprenia les seves «llargues vacances del $36 \%$. Hagué de restar a Orihuela del Tremedal fins el 26 de setembre en que, veient que el conflicte encetat el 18 de juliol no portava camí d'acabar-se ràpidament, prengué el retorn a Barcelona amb tots els seus acompanyants llevat d'un dels estudiants, membre de les JONS, que preferí passar a Burgos, on tenia parents. Anàren a peu fins a Tragacete fent un dia i mig de camí a través de la Sierra $i$ d'allí pogueren arribar a Cuenca $i$ a València per tornar a Barcelona en tren des d'aquesta ciutat. Aquest episodi, que hagués pogut ser simplement una aventura més en la vida més aviat inquieta d'un botànic viatger, esdevingué el 1940 base per a un procés que marginà definitivament la persona i l'obra de Font i Quer de l'esfera pública i el relegà a l'estadi de «ciència oculta» en 9448 , 18 lols trobàrem els anys seixanta. 
Els anys de la guerra foren encara, a desgrat de les dificultats fàcils d'imaginar, anys d'intensa activitat. Tancades les classes a la Universitat, no deixà tanmateix de treballar al Seminari de Botánica de la Facultat de Farmàcia per a continuar el fitxer de cites de localitats ibèriques i marroquines de plantes per a anar constituint la base de la seva projectada Flora Occidentalis. Veient que la situació del Museu de Ciències Naturals a la Ciutadella, prop del port i de l'estació de França, era molt exposada enfront dels bombardeigs, tractà de traslladar-lo a lloc més segur però no ho assolí més que amb l'Institut Botànic que quedà installat el 1937 en una torre de la Bonanova, a carrer de Sant Gervasi. Pugué també salvar l'herbari Sennen del Collegi de la Salle de la Bonanova, molt important en nombre de plecs tot $\mathrm{i}$ que discutible quan al mètode de classificació i determinació (el germà Sennen, sallesiá, era un botànic dels anomenats "polvoritzadors» per tal com descriuen espècies noves amb molta lleugeresa basant-se en diferències insignificants i no constants amb les seves congèneres $i$ era també aferrissat antievolucionista). Encara més important fou el rescat i recuperació en plena guerra de l'herbari i museu Salvador que contenia la més antiga collecció de plantes de Catalunya, algunes procedents de localitats del Pla de Barcelona, ja des aparegudes amb el creixement urbà, una estimable biblioteca $i$ diferents colleccions d'especímens d'història natural malauradament sense cap classifi cació ni indicació de procedència. Aquest herbari, la biblioteca i les colleccions havien estat iniciades a mitjan segle xvı per l'apotecari Joan Salvador $i$ Boscà $i$ notablement enriquides pel seu fill Jaume $i$ els seus dos nets Joan i Josep, després foren continuades amb variable interés pels seus descendents fins que un d'aquests, a mitjan segle XIX (1854?) les traslladà a unes golfes del mas de la Bleda, al Penedès, on romangueren oblidades per espai de vuitanta anys, fins que per una sèrie de circumstàncies afortunades Font i Quer pogué gestionar llur incorporació al patrimoni de l'Institut Botànic i fer-la efectiva en plena guerra, el març de 1938. Una vegada més l'economia de temps i despeses presidí l'operació: entre el decret del Departament de Cultura de la Generalitat i la incorporació efectiva dels materials del museu Salvador després d'haver-los inventariat a la Bleda transcorregueren només quaranta-cinc dies $i$ les despeses pujaren només 1.068 pessetes amb 23 cèntims (xifra més important el 1938 que avui, però que no deixa de ser sense comú mesura amb el tresor recuperat).

Amb la fi de la guerra, però, tot el muntatge pacientment construit per Font i Quer al llarg de més de vint anys rebé de front l'embat de l'odi i de les enveges. Font $i$ Quer fou detingut i processat $i$ hagué de romandre dos anys empresonat al Castell de Montjuic, l'herbari de Carles Pau que havia estat legat per aquest botànic valencià a l'Institut Botànic fou incautat $\mathrm{i}$ traslladat a Madrid. L'Institut Botànic fou reduit novament a mera dependència municipal en el si d'un "Instituto Municipal de Ciencias Naturales» amb dotacions econòmiques limitadíssimes $\mathrm{i}$ amb una progressiva reduccí́ del personal en no cubrir-se les places deixades vacants per les depuracions $\mathrm{i}$ les jubilacions.

Encara que en aquests anys de maltempsada que havien de ser els darrers de la seva vida sabé fer front amb dignitat $\mathrm{i}$ empenta a les adversitats $\mathrm{i}$ una vegada més emprengué la tasca de posar els fonaments nous d'una botánica catalana personalitzada i prestigiosa. El 1942, quan feia poc més d'un any que havia quedat en llibertat provisional pren part en la represa de l'Institut d'Estudis Catalans amb Ramon Aramon i Serra, Miquel Coll i Alentorn, Josep Puig i Cadafalch, Eduard Fontseré, Josep M. ${ }^{a}$ López-Picó, Jordi Rubió i Balaguer, Agustí Duran i Sanpere, Josep M." de Sagarra, Joaquim Folch i Torres, Josep R. Bataller i Higini Anglès. El 1945 inicià una Societat Botànica Catalana que seria el primer embrió de la represa de la Institució Catalana d'Història Natural de la que el 1949 esdevindria Secció. Aquesta Societat de Botànica, després Secció de Botànica de la Institució Catalana d'Història Natural, fou, fins el 1972, el fil tènue de continuitat entre l'activitat científica catalana dels anys anteriors a la guerra $i$ la represa posterior $i$ serví de plataforma d'acollida a botànics estrangers rellevants d'entre els que destaca sobretot Josias Braun-Blanquet, que feu diferents excursions per Catalunya en companyia de Font i Quer i d'alguns joves naturalistes d'aquell temps avui botànics eminents com Oriol de Bolòs o Pere Montserrat (1947-1949).

Els anys de la posguerra són també uns anys de dedicació a la divulgació botànica, als treballs de caire lingüístic o lexicogràfic i, sobre tot, per als qui sou aquí, de la recopilació del seu gran volum de «Plantas Medicinales» que, com sabeu, és molt més que un llibre de plantes medicinals, és d'alguna manera el seu testament. Alli recull totes aquelles coses viscudes en el curs d'una vida dedicada a l'estudi de les plantes i a la organització de la recerca botànica a Catalunya que no havien trobat lloc adequat en les seves publicacions anteriors. Això el fa un llibre alhora amè $\mathrm{i}$ complicat que no es pot llegir linealment sinó que cal anar fullejant en recerca de la sorpresa divertida o colpidora, de la insinuació críptica o illuminadora, de la descoberta engrescadora. El món de les plantes, el món dels homes i el seu món personal $s$ 'hi barregen indestriablement $\mathrm{i}$ arrosseguen de manera inevitable el lector.

En els darrers anys de la seva vida, mentre oficialment es trobava privat de tots els seus càrrecs del periode anterior a la guerra $\mathrm{i}$ reduit només, a partir de 1946, a la condició de naturalista de l'Institut Botànic de Barcelona 
amb unes subvencions simbòliques que el convertien de fet en botànic de dissabtes i diumenges, rebé en canvi honors internacionals no per merescuts menys significatius (Membre del Patronat de l'estació internacional de Biologia Mediterrània de Blanes - Fundació Carles Faust-, el 1951; Vice-President del VIII Congrés Internacional de Botànica de París i Rapporteur de terminologia corològica -és a dir nomenclatura de les àrees de distribució de les plantes- del mateix congrés, el 1954; membre del Consell General de Redacció de Flora Europea el 1956; Doctor Honoris Causa per la Universitat de Montpellier el 1959). El 1963 fou nomenat encara Vice-President del $\mathrm{X}$ Congrés Internacional de Botànica de Edimburg, càrrec que no pogué ocupar en sorprendre'l la mort a la primeria de 1964, mesos abans de que el congrés tingués lloc.

Aquest fou l'home la memòria del qual he volgut honorar. Per més de quaranta anys fou el capdevant de la botànica catalana i reeixí a crear una escola que ha tingut fecunda continuitat; fou reconegut pels seus iguals $i$ detestat pels envejosos incapaços de posar-se al seu nivell; deixà una obra extensa i rica de la que encara avui ens beneficiem en múltiples camps de recerca. Deixà sobretot un exemple de perseverància, d'imaginació, d'energia, de mentalitat oberta a tot allò de nou que pot oferir l'observació del món que ens envolta no solament en el camp específic a que dedicà preferentment la seva recerca sinó en molts d'altres més o menys relacionats. Tant de bo tots sabessim treure profit de les seves lliçons i no haguessim de veure mai més homes com ell humiliats i marginats per un odi cec per la nostra cultura... i potser per tota cultura.

He acabat. 